\title{
KATEKESE PENGHAYATAN EKARISTI DALAM TRADISI KENDURI UMAT PAROKI MARIA RATU DAMAI PURWOREJO MALANG: ANALISIS SHARED PRAXIS APPROACH MENURUT THOMAS H. GROOME
}

\author{
Thomas Onggo Sumaryanto, Antonius Denny Firmanto \\ Sekolah Tinggi Filsafat Teologi Widya Sasana Malang \\ titusajabrandsma@gmail.com \\ rm_deni@yahoo.com
}

\begin{abstract}
This study focuses on the implementation of the Eucharistic appreciation catechesis in the tradition of kenduri by the Parish of Maria Ratu Damai Purworejo Malang. This research method is qualitative with a critical analysis approach. Researchers will use data from pastoral year reports which are the result of direct observation. The formulation of the problem to be answered is how the implementation of catechesis through kenduri in the light of the shared praxis approach according to Groome. Researchers found that the tradition of kenduri carried out by the parishioners of Maria Ratu Damai is indirectly a catechesis of the Eucharistic appreciation. Catechesis is carried out using symbols. The praxis dimension is very visible in the ujub-ujub (prayer) that the leader makes. However, the share dimension is still not strong enough. Therefore, the researcher provides a suggestion to carry out a deepening of faith with a shared praxis approach to strengthen the share dimension.
\end{abstract}

Keywords: catechesis, kenduri, eucharist, shared praxis, Groome

\section{PENDAHULUAN}

Paroki Maria Ratu Damai Purworejo Malang memiliki katekese kontekstual. Katekese kontekstual dilakukan di dalam tradisi kenduri. Katekese ini dilakukan oleh para asisten imam yang merupakan sesepuh desa. Doa (ujubujud) dipanjatkan dengan tradisi Gereja Katolik. Semua umat berkumpul di tengah-tengah makanan yang telah disajikan dan pemimpin akan berdoa sambil menjelaskan makna dari simbol-simbol yang ada. Penjelasan ini disesuaikan dengan ajaran iman dasar Katolik seperti karya keselamatan dalam Tritunggal Mahakudus. Ada kemungkinan pada waktu awal pembangunan paroki, para katekis berusaha membangun katekese yang benar-benar menyentuh kebudayaan 
setempat. Sebenarnya katekese ini bisa digunakan untuk penguatan nilai penghayatan ekaristi.

Kekayaan rohani Ekaristi perlu diintegrasikan dalam pendidikan kristiani atau katekese. Katekese merupakan pengajaran iman kepada semua anggota Gereja (Jelahu 2016:169). Tujuannya adalah mematangkan iman awal dan mendidik murid Kristus yang sejati dengan pengetahuan yang lebih mendalam dan lebih sistematis tentang Pribadi dan pesan Tuhan kita Yesus Kristus (bdk. Catechesi Trandendae no. 19). Akhirnya pendidikan ini menjadi dialog iman umat beriman, yang mendorong ke arah keterlibatan dan solidaritas sebagai murid Kristus sejati (Pranyoto 2018:56).

Thomas H. Groome menyatakan bahwa katekese harus memiliki sebuah pedagogi yang membawa hidup umat kepada iman dan imannya pada kehidupan sehari-hari (2006:53). Katekese kontekstual harus memiliki pedagogi ini. Dengan kata lain, katekese kontekstual yang sudah dibentuk di Paroki Maria Ratu Damai harus membimbing umat memiliki iman yang hidup. Pelaksanaan katekese dalam tradisi kenduri harus mampu membawa kehidupan kepada iman dan iman kepada kehidupan. Groome memiliki sebuah pendekatan yang ia namai shared praxis. Dengan pendekatan ini, Groome menegaskan bahwa katekis harus mempunyai komitmen yang kuat untuk menciptakan komunitas di mana umat dapat bertumbuh kembang. Bahkan pendekatan ini dapat dimodifikasi sesuai dengan konteks paroki (Groome 2006:764).

Penelitian ini berusaha menganalisis katekese penghayatan ekaristi dalam tradisi kenduri dengan bantuan analisis pendekatan Groome. Rumusan masalah yang ingin dijawab adalah:

1. Bagaimana pelaksanaan katekese dalam tradisi kenduri umat Paroki Maria Ratu Damai Purworejo Malang?

2. Bagaimana katekese penghayatan ekaristi nampak dalam tradisi kenduri Paroki Maria Ratu Damai Purworejo Malang?

3. Bagaimana analisis konsep katekese dalam kenduri ini menurut teori shared praxis?

Penelitian ini memiliki kesamaan dengan beberapa penelitian sebelumnya. Pertama, Robert Pius Manik meneliti ritual maggid sebagai model berkatekese (2018). Ritual ini merupakan bagian liturgi Yahudi. Model ritual ini dapat digunakan untuk katekese liturgi secara khusus menekankan bagaimana umat dapat membatinkan pengalaman iman dalam perayaan liturgi Gereja. Kedua, Donatus Sermada Kelen meneliti tradisi Semana Santa sebagai bentuk katekese (2018) Tradisi ini merupakan perayaan khas pekan suci oleh umat Katolik di Larantuka. Tradisi ini menjadi katekese yang hidup dalam bentuk devosi. Namun tradisi ini harus benar-benar dijaga supaya penghayatan iman umat tidak terbatas 
pada superfisialisme. Kebaruan dari penelitian ini sendiri adalah analisis kritis pada pelaksanaan katekese kontekstual di Paroki Maria Ratu Damai Purworejo Malang. Peneliti menggunakan pemikiran Groome untuk menganalisisnya.

Metode penelitian ini adalah kualitatif dengan pendekatan analisis kritis. Peneliti akan menggunakan data dari laporan tahun pastoral yang merupakan hasil observasi langsung. Peneliti telah menjalani masa praktek pastoral pada Agustus 2019 sampai Juni 2020. Selama masa praktek ini, peneliti mengikuti katekese dalam tradisi kenduri. Peneliti berdialog dengan para asisten imam mengenai proses pelaksanaan tradisi ini dalam terang iman Katolik. Data penelitian ini memiliki konteks upacara unggah penuwun dan misa arwah. Data tersebut dianalisis kembali dengan bantuan pemikiran Thomas H. Groome tentang a shared praxis approach (2006). Penelitian ini bersifat konseptual.

\section{PEMBAHASAN}

\subsection{Landasan Pemikiran}

\subsubsection{Nilai-nilai Penghayatan Ekaristi Dalam Ensiklik Ecclesia de Eucharistia}

Ekaristi adalah perayaan resmi iman Gereja. Semua umat berkumpul dan merayakan misteri paskah yang merupakan rahmat keselamatan bagi umat manusia. Oleh sebab itu, Ekaristi merupakan puncak seluruh kehidupan Gereja (LG 11). Kehidupan beriman Gereja bersumber dari Ekaristi dan akhirnya Ekaristi membangun Gereja. Paus Yohanes Paulus II menjelaskan bahwa setiap kali umat merayakan Ekaristi, umat juga merayakan karya keselamatan sekaligus kelahiran Gereja (John Paul II 2003:5).

Dalam ensiklik Ecclesia de Eucharistia, Paus Yohanes Paulus II menekankan ekaristi mempunyai sifat apostolik (John Paul II 2003:28). Gereja dibangun atas pondasi para rasul dan menjadi saksi untuk melanjutkan karya misi Yesus Kristus. Ekaristi dirayakan mengacu para iman para Rasul. Gereja selalu dikuduskan dan dibimbing oleh para rasul untuk sampai kepada Kristus. Oleh sebab itu kehadiran seorang imam tertahbis sebagai pemimpin Ekaristi mutlak diandaikan. Imam memiliki jabatan yang serahkan oleh Uskup sehingga ia melanjutkan tugas para rasul. Namun umat Allah juga turut berpartisipasi penuh berdasarkan imamat rajawi mereka (John Paul II 2003:28).

Paus Yohanes Paulus II ingin mengingatkan kembali bahwa perayaan Ekaristi memiliki hubungan erat dengan kehidupan sehari-hari (Martasudjita 2013:279). Umat mendapatkan kekuatan rohani melalui perayaan ini. Kekuatan ini mendorong setiap anggota Gereja untuk menjadi saksi Kristus di tengah dunia. Gereja terus didorong untuk mewartakan keadilan dan perdamaian dunia. Dimensi eskatologis dari perayaan Ekaristi mendorong umat Allah untuk melakuan perwartaan keadilan dan perdamaian dunia (Ristanto 2020:124). 
Dimensi eskatologis Ekaristi begitu diserukan oleh Paus Yohanes Paulus II. Ekaristi yang dirayakan oleh Gereja berkaitan erat dengan kehidupan surgawi. Umat Allah berusaha mendapatkan kepenuhan sukacita yang dijanjikan oleh Kristus sendiri (Yoh 15:11) yaitu kedatangan-Nya yang kedua di dunia. Selain itu jaminan akan kebangkitan tubuh pada akhir jaman dirayakan di dalam Ekaristi. Paus Yohanes Paulus II menegaskannya dengan janji Kristus sendiri yaitu Barangsiapa makan Tubuh-Ku dan minum Darah-Ku akan memiliki hidup Kekal (Yoh 6:54) (2003:18). Dengan menyantap Tubuh dan Darah Kristus dalam perayaan Ekaristi, umat Allah mendapatkan jaminan kehidupan kekal. Oleh sebab itu umat Allah mengungkapkan persekutuan dengan Gereja Surgawi.

Konsekuensi dari persekutuan ini adalah peziarahan umat Allah di dunia harus mencerminkan semangat eskatologis. Janji akan hidup baru di surga tidak mengurangi tanggung jawab manusia di dunia. Ekaristi berkaitan erat dengan kehidupan sehari-hari. Paus Yohanes Paulus II mengajak semua anggota Gereja untuk menyumbang kebaikan untuk pembangunan dunia yang lebih baik (2003:20). Perdamaian dan keadilan harus tetap diperjuangkan sehingga sesuai dengan rencana Allah. Ekaristi mempunyai dimensi sosial yaitu bagaimana mewujudkan dunia yang penuh dengan kasih (Ristanto 2020:125).

Dalam konteks Indonesia, hubungan Ekaristi dengan kehidupan sehari-hari sering digambarkan dengan metafora altar dan pasar (Martasudjita 2013:281) Perayaan di altar dikaitkan erat dengan kehidupan sehari-hari di pasar. Yang menjadi titik permasalahan adalah bagaimana keterkaitan ini dijelaskan sekaligus dihayati oleh semua anggota Gereja. Ekaristi harus dihayati sebagai kekuatan rohani untuk pewartaan kasih di tengah dunia. Umat Allah semakin disadarkan bahwa dengan Ekaristi, mereka mendapatkan tugas sebagai perpanjangan pewartaan karya keselamatan di tengah dunia. Ekaristi memberikan semangat meskipun umat Allah memiliki banyak tantangan hidup. Oleh sebab itu, peran katekese tentang penghayatan nilai-nilai Ekaristi perlu ditingkatkan.

\subsubsection{Teori A Shared Praxis Approach}

Thomas H. Groome adalah seorang profesor teologi dan pendidikan religius. Dia dilihat sebagai seorang ahli dalam pendidikan kristiani (katekese) dan memberikan sumbangan besar dalam metode berkatekese (Nagle 2019:2). Dia memiliki fokus pada pelaksanaan katekese yang dilakukan oleh Gereja Katolik. Metode katekese yang ia tawarkan adalah pendekatan shared praxis. Metode ini merupakan sebuah pedagogi yang berusaha untuk mendampingi umat membawa seluruh hidupnya pada imannya dan membawa imannya pada hidup (Groome 2006:763). Groome ingin mencapai satu tujuan yaitu umat memiliki iman yang hidup. 
Untuk mencapai iman yang hidup, Groome menyatakan bahwa perlu ada komunitas/kelompok dialog di antara umat (2006:764). Kelompok ini akan menjadi sebuah wadah setiap umat belajar dari pengalaman satu sama lain. Mereka selalu diajak untuk mengungkapkan perjuangan imannya dan saling memberikan nasehat satu sama lain. Selain itu kehadiran katekis atau imam sangat diperlukan dalam proses ini. Katekis tidak hanya mengajarkan ajaran iman tetapi mengajak umat untuk merefleksikan hidupnya sehingga terjadilah proses pembatinan iman.

Groome melihat teorinya sebagai sebuah pendekatan (an approach) bukan sebuah metode (2006:765). Pendekatan ini membutuhkan keyakinan bahwa katekis menjadi emansipatoris bagi umat dan mempercepat umat untuk aktualisasi iman di dunia dengan penuh rasa tanggung jawab. Dengan kata lain a shared praxis approach memiliki pola kata kunci mengajar dan belajar (teachinglearning).

Katekese merupakan sebuah proses untuk penguatan identitas umat sebagai orang Kristiani (Mahon 2018:23). Groome sendiri tidak membedakan begitu tajam antara pendidikan religius dan katekese (2006:766). Kedua hal ini merupakan satu kesatuan. Pendidikan religius bersifat akademik dan katekese lebih menekankan sifat eklesial (Groome 2018:147). Kedua sifat ini justru sangat mendukung dan membantu perkembangan iman umat. Dengan a shared praxis approach, Groome menawarkan sebuah pendidikan yang bersifat katekese. Pendidikan harus memberikan dampak positif dalam kehidupan umat dan masyarakat. Dengan demikian umat dibawa untuk belajar dari kehidupannya sendiri daripada belajar dari teori-teori.

Proses belajar dari kehidupan sungguh menekankan dinamika kognisi manusia. Umat akan dibawa untuk memahami materi sekaligus diundang untuk memutuskan dan menyimpulkan sendiri materi bagi kehidupannya. Dinamika ini diharapkan dapat menggerakkan pikiran, hati, dan tangan umat untuk menghidupi imannya dalam kehidupan sehari-hari (Groome 2006:767). Komunitas menjadi wadah dinamika iman. Umat bisa mengidentifikasi dirinya sebagai orang yang harus memiliki iman yang hidup dan berbagi (Nagle 2019:6).

Selanjutnya Groome menjelaskan makna frasa a shared praxis. Praxis mengarah pada sebuah aktivitas manusia penuh arti. Semuanya dilakukan dengan penuh refleksi. Groome sendiri menggunakan praxis untuk menunjukkan aktivitas manusia yang memiliki 3 dimensi yaitu reflektif, aktif, dan kreatif (2006:769). Dimensi reflektif menunjukkan keseluruhan kapasitas manusia untuk mengetahui melalui akal, ingatan, dan imajinasi. Dimensi aktif menunjukkan perhatian manusia terhadap kehidupan dunia. Dimensi kreatif menunjukkan daya di dalam diri manusia untuk melakukan sesuatu sesuai yang didapatkan melalui dimensi reflektif dan aktif. 
Dalam konteks iman Kristiani, praxis merupakan sebuah proses di mana umat diajak untuk melihat Tuhan selalu menampakkan Diri-nya dalam kehidupan sehari-hari. Umat membatinkan kehadiran-Nya melalui hidupnya sendiri. Kehadiran-Nya begitu nyata di dalam Kitab Suci dan Tradisi. Ajaran di dalam Kitab Suci dan Tradisi harus menjadi perhatian utama dalam proses katekese hingga akhirnya umat sampai pada titik bahwa Tuhan selalu hadir. Groome menyebut materi ajaran Kitab Suci dan Tradisi sebagai Christian Story and Vision (Tradisi dan Visi Kristiani). Penyebutan ini dianggap sebagai sebuah metafora yang menggambarkan keseluruhan realitas historis wahyu Kristiani dan janji Kristus yang membuat umat hidup di dalam komunitas Kristiani (Groome 2006:770).

Kata shared menekankan dinamika komunal yang ditemukan dapat proses katekese. Dinamika komunal yang dimaksud adalah dialog dan integrasi antara tradisi dan visi (situasi sekarang) partisipan dan tradisi dan visi Kristiani di dalam komunitas (Groome 2006:770). Semua partisipan berdialog, belajar bersama, dan bersaudara satu sama lain dalam iman. Dalam proses ini mereka saling mendengarkan, bertukar pikiran, berbagi pengalaman, mengutarakan pendapat dan sebagainya (Johnson-Miller dan Espinoza 2018:160). Secara tidak langsung setiap partisipan saling berbagi dan menemukan identitas sejati sebagai orang Kristiani. Akhirnya tujuan akhir dari pendekatan ini adalah refleksi mendalam sebagai dorongan untuk komunitas yang memiliki iman yang hidup.

Dinamika dalam a shared praxis approach membutuhkan langkahlangkah pedagogi. Pola pedagogi yang harus ditekankan adalah membawa kehidupan kepada iman dan iman kepada kehidupan. Groome memberikan sebuah contoh bentuk pendekatan ini. Dia memberikan bentuk ini dalam konteks komunitas. Sebelum itu para katekis harus menentukan dahulu fokus katekese. Berikut langkah-langkah pendekatan ini:

\begin{tabular}{|l|l|}
\hline $\begin{array}{l}\text { Langkah Pertama } \\
\text { Pengungkapan } \\
\text { Pengalaman } \\
\text { Hidup Sehari-hari }\end{array}$ & $\begin{array}{l}\text { Para peserta dibimbing untuk melihat pengalaman hidupnya } \\
\text { sesuai dengan fokus/tema yang ingin dicapai. Mereka bisa } \\
\text { mengungkapkannya melalui cerita, gambar, atau simbol-simbol. } \\
\text { Kunci langkah pertama ini adalah peserta memperhatikan tema } \\
\text { dalam pengalaman hidup sehari-hari. }\end{array}$ \\
\hline & $\begin{array}{l}\text { Setelah melihat pengalaman masing-masing, para peserta diajak } \\
\text { untuk merefleksinya secara kritis. Refleksi kritis ini berusaha }\end{array}$ \\
Langkah Kedua & $\begin{array}{l}\text { membimbing akal, ingatan, atau imajinasi peserta. Mereka diajak } \\
\text { Refleksi Kritis } \\
\text { pada pengalaman }\end{array}$ \\
& $\begin{array}{l}\text { memahami situasi bagaimana pengalaman itu bisa terjadi. } \\
\text { Akhirnya peserta diajak untuk mengetahui pentingnya tema } \\
\text { dalam kehidupan sehari-hari. }\end{array}$ \\
\hline $\begin{array}{l}\text { Langkah Ketiga } \\
\text { Tradisi dan Visi }\end{array}$ & $\begin{array}{l}\text { Para peserta diajak untuk mendalami ajaran iman Kristiani } \\
\text { sebagai sumber spiritual kehidupan. Kitab Suci menjadi salah satu }\end{array}$ \\
\hline
\end{tabular}




\begin{tabular}{|l|l|}
\hline Kristiani & $\begin{array}{l}\text { sumber Tradisi dan Visi Kristiani. Para katekis harus mampu } \\
\text { mendampingi para peserta untuk memahami salah teks Kitab Suci } \\
\text { yang sesuai dengan tema. Tujuan yang ingin dicapai adalah para } \\
\text { peserta memahami bagaimana ajaran iman Kristiani memberikan } \\
\text { semangat spiritual dalam kehidupan sehari-hari. }\end{array}$ \\
\hline & $\begin{array}{l}\text { Bagian ini merupakan pendalaman langkah pertama, kedua, dan } \\
\text { ketiga. Setelah mendapatkan inspirasi dari ajaran Kristiani dan } \\
\text { melihat pengalaman hidup, peserta diajak untuk membatinkan } \\
\text { Langkah Keempat } \\
\text { Pembatinan } \\
\text { Inspirasi Iman } \\
\text { Kristiani pada } \\
\text { Kehidupan }\end{array}$ \\
$\begin{array}{ll}\text { kesadaran baru dalam proses menjadi orang Kristiani. } \\
\text { Pendamping bisa memberikan pertanyaan untuk proses } \\
\text { pembatinan. Namun yang harus ditekankan adalah para peserta } \\
\text { harus mengikuti isi hati masing-masing. Pendamping menghargai } \\
\text { semua usaha pembatinan peserta. }\end{array}$ \\
\hline Langkah Kelima \\
Niat Pribadi & $\begin{array}{l}\text { Para peserta diberi kesempatan untuk memilih dan memutuskan } \\
\text { untuk menjawab kesadaran dan inspirasi yang mereka dapatkan di } \\
\text { dalam iman Kristiani. Pendamping memberikan pertanyaan untuk } \\
\text { mengungkapkan niat-niat peserta. Mereka harus diarahkan untuk } \\
\text { membuat sebuah keputusan niat dalam kehidupan sehari-hari. } \\
\text { Niat ini menjadi langkah awal pertobatan menjadi manusia yang } \\
\text { lebih sempurna. }\end{array}$ \\
\hline
\end{tabular}

Groome memberikan sebuah catatan bahwa pendekatan ini bersifat fleksibel (Groome 2006:775). Lima langkah dapat disesuaikan dengan waktu dan situasi. Para pendamping dapat melihat konteks para partisipan. Pendekatan ini dapat diadaptasikan dalam konteks apa pun. Dengan kata lain, teori Groome juga dapat digunakan dalam katekese kontekstual. Indonesia memiliki banyak latar belakang suku dan budaya. Tujuan utama pendekatan a share praxis adalah membawa kehidupan kepada iman dan iman kepada kehidupan. Tradisi dalam kebudayaan adalah bagian dari kehidupan. Katekese kontekstual dapat menjadi salah satu cara membawa umat pada dinamika ini.

\subsection{Hasil Penelitian}

\subsubsection{Tradisi Kenduri di Paroki Maria Ratu Damai}

Pada tahun 2019, Paroki menyambut pesta intan yaitu 60 tahun. Jumlah umat adalah 754 KK (1799 orang). Yang jelas paroki ini masih mempertahankan kekhasan yaitu budaya Jawa. Bahasa sehari-hari yang digunakan adalah bahasa Jawa dan Indonesia. Perhitungan kalendar Jawa masih dipertahankan. Banyak juga acara adat yang masih dipertahankan seperti bersih desa, kenduri, suro, dan lain-lain. Para warga sekitar masing memegang teguh upacara tersebut. Satu hal yang menarik adalah renovasi gedung gereja. Peneliti mendapatkan kesempatan untuk melihat proses renovasi gereja. Renovasi ini selalu diiringi dengan beberapa 
upacara seperti penanaman paku emas, unggah panuwun, dan kenduri. Umat paroki masih mempertahankan budaya dalam membangun rumah. Upacara ini hanya ingin memohon rahmat dari Allah sendiri supaya renovasi berjalan dengan lancar. Namun perlu upacara ini perlu direfleksikan ulang supaya tidak terkesan memaksakan nilai-nilai iman Katolik dan nilai budaya Jawa.

Saat pertama kali mengikuti misa arwah di salah satu stasi, peneliti melihat banyak orang berkumpul untuk berdoa bersama melalui tradisi kenduri tidak peduli agamanya apa. Meskipun rumah ini adalah keluarga Katolik, warga desa yang beragama Islam juga ikut. Peneliti bertanya kepada umat bahwa apakah hal ini sudah biasa dilakukan. Beliau pun menjawab bahwa jika ada kenduri dan tetangga tidak hadir, hal ini merupakan sebuah tindakan mengasingkan diri dari desa.

Tradisi kenduri ini merupakan acara di mana semua warga desa harus berkumpul dan berdoa bersama (Cahyani, Karsidi, dan Kartono 2019:4). Jika ada warga yang tidak datang, biasa langsung segera diketahui warga lain dan bisa menjadi bahan gosip. Bahkan dia bisa dianggap tidak mau bersosialisasi dengan desa. Apapun yang terjadi, kecuali karena sakit, warga desa harus mengikuti tradisi ini. Tradisi ini menjadi sebuah bukti eksistensi sebuah desa. Bahkan jika ada keluarga yang ingin mengadakan kenduri, tetangga atau kerabat yang dekat akan membantu untuk mempersiapkan segala sesuatu yang dibutuhkan. Di balik tradisi ini ada budaya gotong royong yang begitu kuat (Arifianto, Nurman, dan Dewi 2018:274).

Jika ada warga yang tidak membantu, hal ini bisa menjadi masalah di kemudian hari. Jika warga tersebut mengalami kesusahan, warga lain enggan menolong. Tradisi ini begitu penting bagi warga desa Donomulyo. Setiap acara doa arwah atau syukuran desa, pasti ditemukan tradisi ini. Banyak para sesepuh desa mengatakan bahwa tradisi ini adalah cara orang Jawa berdoa sebelum agamaagama masuk ke pulau Jawa. Para sesepuh desa percaya bahwa nenek moyang orang Jawa sudah punya tradisi berdoa. Menurut peneliti, ini adalah kesadaran rohani yang luar biasa. Sebelum agama masuk, orang Jawa sudah punya tradisi berdoa dan mereka berdoa secara komunitas. Selain itu tradisi ini menjadi eksistensi desa. Peneliti memahami jika ada salah satu umat kecewa jika romo atau frater atau suster yang menolak untuk datang mengikuti tradisi ini. Setidaktidaknya para petugas pastoral harus mengikutinya meskipun sulit memahami bahasa Jawa.

Peneliti melihat kenduri merupakan tradisi doa dengan berbagai intensi. Tidak terbatas pada doa arwah, kenduri biasanya dilakukan setelah misa natal atau paskah, acara syukuran pernikahan, sunatan, dan sebagainya. Hampir semua stasi Paroki Purworejo melakukan kenduri. Kenduri tidak bisa dilepaskan dari kehidupan umat paroki. Mereka harus berdoa dengan tradisi ini. Dalam penelitian 
ini, tradisi kenduri dilihat dalam 2 acara saja. Pertama, kenduri dalam acara unggah penuwun (penaikan rangka utama atap rumah) dan kedua, kenduri dalam doa arwah.

Unggah Penuwun merupakan sebuah upacara dalam membangun rumah. Pada bulan September 2019, Paroki Purworejo memulai untuk merenovasi gedung gereja. Renovasi yang dilakukan adalah perbaikan atap gereja. Saat proses renovasi berlangsung, ketua wilayah pusat langsung menemui pastor paroki. Beliau meminta ijin untuk melakukan upacara unggah penuwun. Tradisi ini memiliki nama lain munggah molo (Purwandaru, Wiyancoko, dan Ueda 2016:73). Tradisi unggah penuwun mempunyai banyak simbol seperti kain merah, bendera merah putih, telur ayam kampung, aneka bunga, dan sebagainya. Semuanya harus disediakan dalam keadaan baru dan baik. Jika tidak, umat beranggapan malapetaka akan terjadi. Hal ini mau menunjukkan kebudayaan Jawa kaya akan simbol-simbol atau lambang-lambang. Ada kemungkinan besar, orang Jawa terbiasa menyampaikan simbol-simbol yang lebih konkret untuk menyampaikan ide dan gagasannya (Yurisma dan Bahruddin 2020:104).

Pada waktu itu ada sesepuh yang dipercaya untuk memimpin upacara ini. Beliau bernama Pak Tris. Umat mengambil kayu jati dan dibungkus dengan kain merah. Setelah Pak Tris mengundang pastor paroki untuk memberkati kayu ini. Kayu ini menjadi simbol penyangga utama bangunan Gereja. Kain merah dipilih untuk membungkus kayu tersebut. Kain ini merupakan simbol kehidupan. Pak Tris menjelaskan bahwa Gereja ini diharapkan akan terus hidup dan bisa menjadi tempat berdoa. Kalau dibandingkan dengan tradisi unggah penuwun rumah biasa, kain yang digunakan adalah baju. Ada berbagai makna yang ingin disampaikan, namun intinya baju itu merupakan lambang perlindungan. Rumah dianggap sebagai tempat berlindung.

Sebenarnya pada waktu itu peneliti sulit untuk memahami doa yang dipimpin oleh Pak Tris karena menggunakan bahasa Jawa Krama Inggil. Setelah pemberkatan kayu selesai, peneliti sedikit berdialog dengan Pak Tris. Rupanya tradisi ini sedikit dimodifikasi dengan ajaran Gereja Katolik. Pak Tris adalah katekis paroki dan membuat semua doa sesuai dengan ajaran Gereja Katolik. Dia sedikit bercerita bagaimana beliau memasukkan unsur Trinitas, sifat-sifat Gereja, dan sebagainya. Namun intinya doa yang dipanjatkan adalah sebuah permohonan umat agar Gereja tetap kuat dan hidup sampai akhir zaman. Setelah mendengar sedikit cerita ini, peneliti mulai sedikit memahami bagaimana cara orang Jawa Katolik berdoa. Doa mereka tidak jauh dari kehidupan sehari-hari. Segala simbol dari alam digunakan sebagai doa. Mereka melihat tanda kehidupan dari alam dan simbol ini menjadi anugerah tersendiri bagi mereka. 


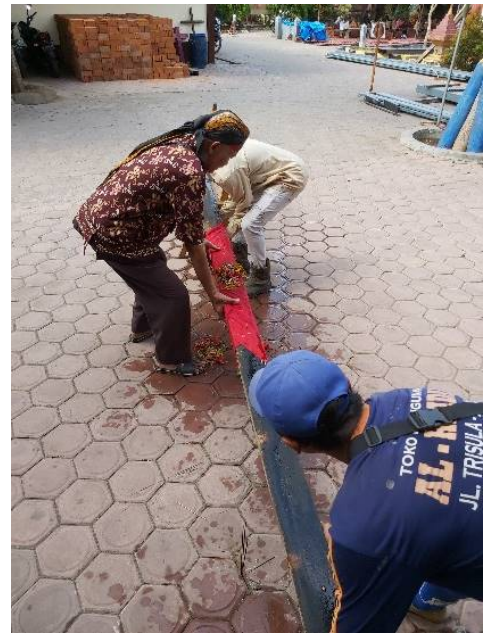

Foto 1 Kayu Penuwun

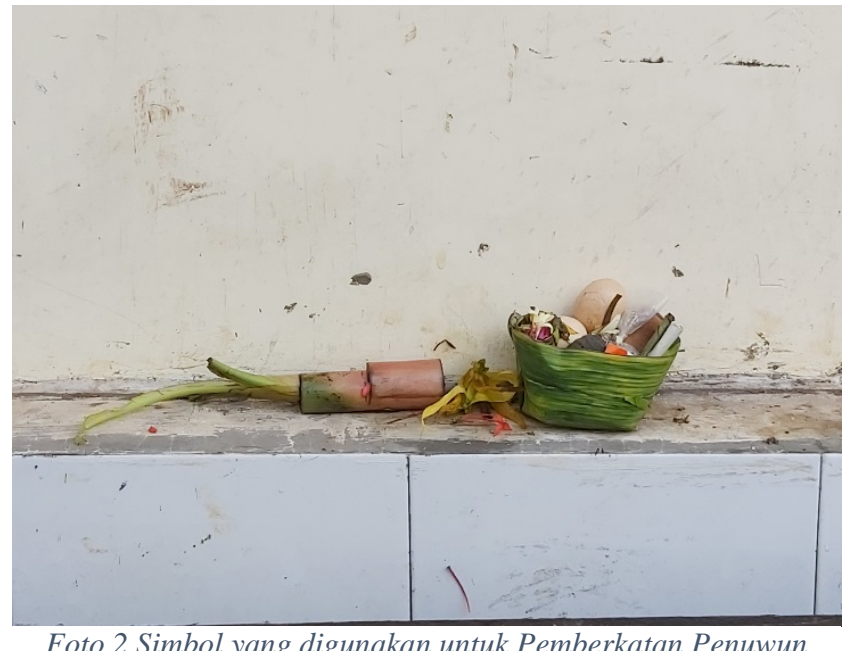

Foto 2 Simbol yang digunakan untuk Pemberkatan Penuwun

Setelah kayu penuwun dinaikkan, kenduri dilakukan di dalam gedung gereja. Kenduri ini bersifat lebih ke arah ucapan syukur dan permohonan (Prastyo dan Maryaeni 2017:30). Istilah lain yang digunakan biasanya slametan (Muhammad Nurul Fadillah, Harles Anwar 2020:3). Namun kenduri harus dilaksanakan di dalam gedung gereja yang akan direnovasi. Jadi sehari sebelum upacara umat membersihkan sedikit gedung gereja supaya bisa digunakan untuk kenduri. Semua bergotong royong untuk kelancaran upacara sederhana ini.

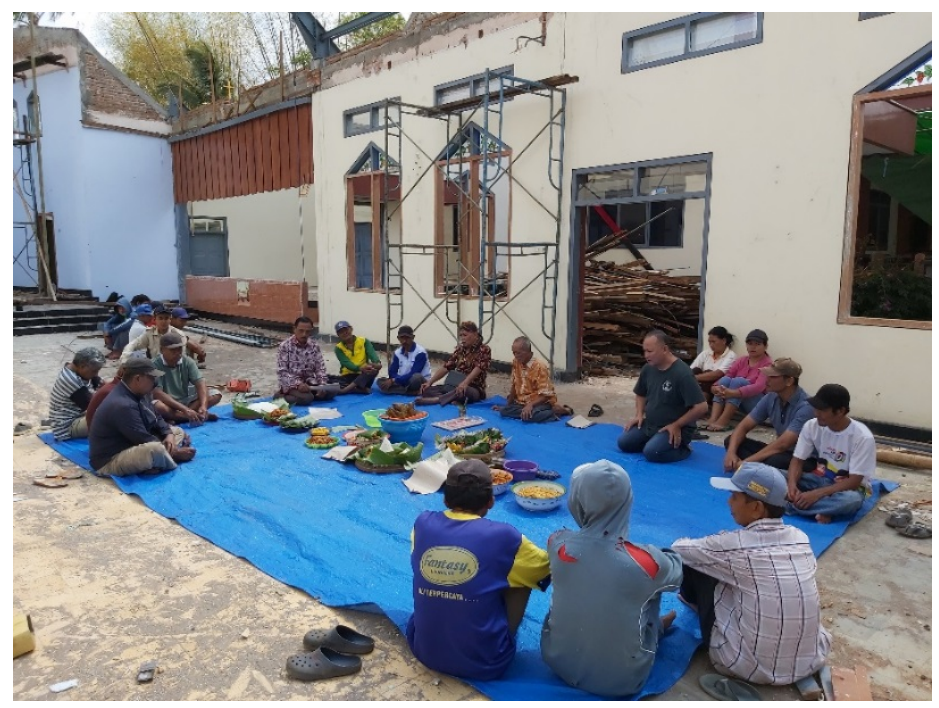

Foto 3 Kenduri setelah upacara unggah penuwun

Tradisi kenduri seperti acara makan bersama (Muhayir 2018:80). Namun sebelum makan ada doa bersama. Pak Tris sebagai sesepuh bertugas untuk memimpin doa (ujub-ujub). Semua makanan diletakkan di tengah-tengah umat dan semua umat duduk melingkari makanan tersebut. Makanan yang harus disediakan adalah ayam ingkung, mie, sambal kental, urap-urap, dan nasi gurih. Selain ada beberapa tambahan jajanan pasar dan buah pisang. Semua yang disediakan ini merupakan simbol intensi doa. Pak Tris memimpin seperti orang tua menasehati anak-anaknya. Doa ini biasanya disusun seperti ini. Pertama, pemimpin mengajak semua orang berkumpul dan menjelaskan makna kehidupan. Kedua, pemimpin menjelaskan simbol makanan yang berada di tengah lingkaran 
warga dan warga menjawab dengan "inggih”. Ketiga, pastor paroki dipersilahkan untuk memerciki dengan air kembang sebagai lambang berkat pada makanan dan semua makanan dibagikan kepada semua orang yang hadir.

Pada bagian pertama, pemimpin akan menjelaskan intensi dari doa dalam kenduri. Pada intinya, tradisi kenduri mau menunjukkan Allah memberikan rahmat-Nya melalui hasil alam yang manusia peroleh. Manusia juga ikut mempersembahkannya kepada Tuhan sebagai ucapan syukur atas kurban penyelamatan dari Allah sendiri. Berikut ajakan pemimpin pada saat kenduri:

\begin{tabular}{|c|c|}
\hline 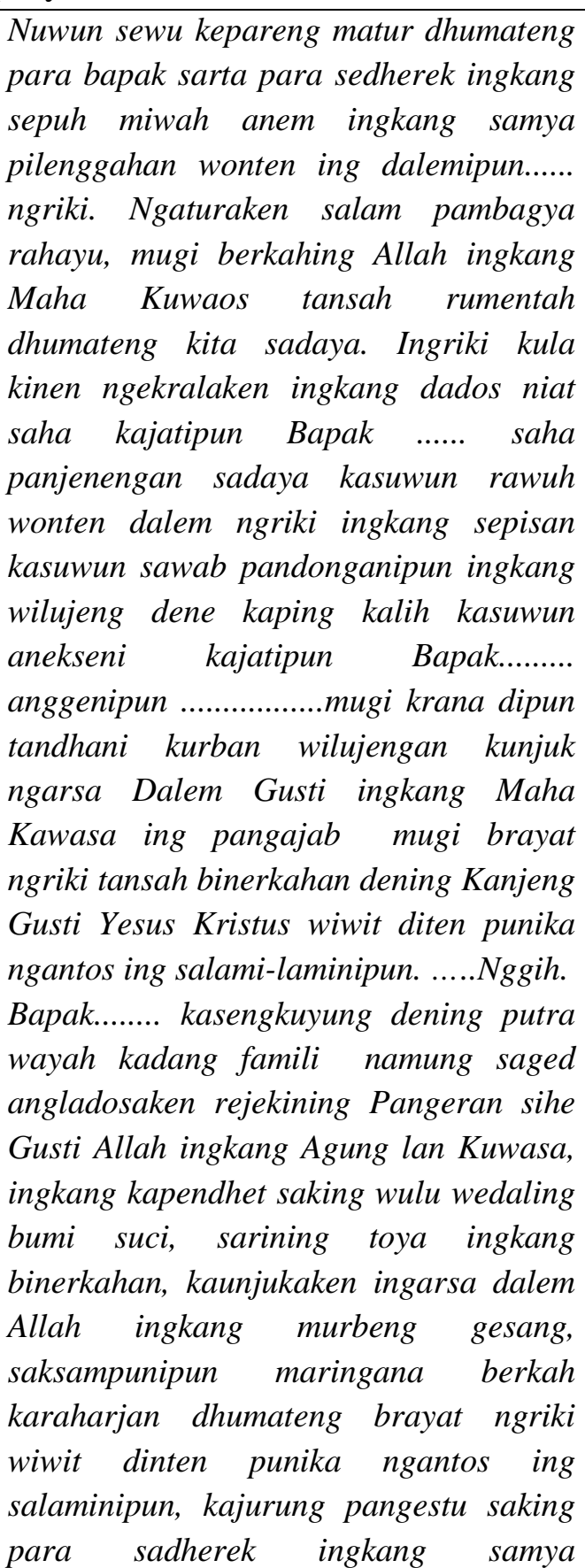 & $\begin{array}{l}\text { baik tua maupun muda yang } \\
\text { luduk hadir di rumah .....(nama } \\
\text { rumah)..... ini. Kami ucapkan } \\
\text { datang dan salam sejahtera. } \\
\text { berkah Allah yang Mahakuasa } \\
\text { a melimpah atas kita semua. Atas } \\
\text { an tuan rumah, perkenankan saya } \\
\text { akan apa yang menjadi niat dan } \\
\text { 3apak ..... Anda semua diundang } \\
\text { sini dengan tujuan: pertama, } \\
\text { doa restu keselamatannya; } \\
\text { dimohon menjadi saksi atas } \\
\text { Bapak ... dalam rangka ..... } \\
\text { berkat ungkapan kurban } \\
\text { bagi Tuhan Allah yang maha } \\
\text { luarga di sini memperoleh berkah } \\
\text { an Yesus Kristus, mulai hari ini } \\
\text { sampai selama-lamanya ...... } \\
\text { a). } \\
\text {... didukung oleh anak cucu, } \\
\text { dan kerabat berkehendak hanya } \\
\text { angkan rejeki dari Tuhan, rahmat } \\
\text { llah maha agung dan kuasa, yang } \\
\text { lari hasil bumi suci, sari dari air } \\
\text { erberkati, dipersembahkan di } \\
\text { Tuhan penguasa kehidupan, } \\
\text { larapan memberi berkah kepada } \\
\text { ini mulai saat ini sampai } \\
\text { a, terdorong doa restu saudara- } \\
\text { yang hadir duduk semua..... } \\
\text { a). } \\
\text { ata rangkaian kurban keselamatan }\end{array}$ \\
\hline
\end{tabular}


pilenggahan sedayanipun ...... Nggih.

Wodene tata rakiting kurban wilujengan kang ginelar punika mujudaken sasmitaning donga kang binerkahan lan kapara-para ingkang satunggal aturan : Wilujengan kang ginelar punika mujudaken raos atur panuwun dhateng ngarsa Dalem Gusti ingkang Maha Kuwaos ingkang sampun anitahaken Ibu bumi Bapa akasa, Ibu wengi Bapa rina, Bapa Adam Ibu Kawa, para Santo, Santa lan para suci tumedhakipun dhumateng kawula dasih ingkang samya andon lampah wonten ing alam ndonya, mugi paringa berkah kawilujengan karaharjan, wiwit dinten punika ngantos ing salami-laminipun kajurung pangestu saking para sadherek ingkang samya pilenggahan sedayanipun .....Nggih. sesungguhnyalah sebagai persembahan: Selamatan yang tersaji ini merupakan ungkapan rasa syukur terima kasih kepada Tuhan yang maha kuasa, yang telah menciptakan Ibu Pertiwi- Bapa Akasa, Ibu Malam-Bapa Siang, Bapa Adam dan Ibu Hawa, para santo-santa, serta para suci hingga masyarakat biasa yang sedang berziarah di dunia. Semoga berkah keselamatan dan kesejahteraan, mulai hari ini sampai selama-lamanya terdorong restu Anda semua yang sedang hadir ....... (Amin).

Pada bagian kedua, pemimpin akan menjelaskan semua simbol doa yang digunakan. Ayam ingkung dilambangkan sebagai Kristus yang tersalib. Pemimpin berkatekese tentang karya penyelamatan Allah melalui jalan salib. Ayam yang telah dimasak melambangkan Yesus telah wafat untuk menebus dosa manusia.

\begin{tabular}{|l|lr|}
\hline Ingkang satunggal aturan, sageda & Yang satu persembahan lagi, kurban \\
linambaran iman kapitayanipun, agami & sembelihan yang disampaikan \\
ingkang dipun ugemi dadosa sarana & merupakan lambang Tuhan Yesus \\
kangge nggayuh kasampurnaning gesang & Kristus yang telah bersedia sengsara, \\
lantaran Sang Kristus, tumunten mbenjing & wafat dengan menuntaskan darah-Nya \\
saged ndherek ngraosaken wohing & di Golgota sebagai tebusan dosa dunia \\
panebusan Dalem, amargi saking jurung & untuk keselamatan umat semua mulai \\
pangestu saking para sedherek ingkang & hari ini hingga selama-lamanya \\
samya pilenggahan sedayanipun......Nggih. & terdorong restu Anda semua yang duduk \\
& hadir di sini ...... (Amin). \\
\hline
\end{tabular}

Kemudian ada kue apem yang melambangkan kerahiman Allah. Pemimpin mengajak semua orang untuk memohon pengampunan agar diberi keselamatan oleh Allah.

\begin{tabular}{|l|l|}
\hline Ingkang satunggal aturan anggenipun & Persembahan berupa apem ini merupakan \\
ngrakit apem saha kolak ketan punika & ungkapan rasa penyesalan, dilanjutkan \\
mujudaken raos keduwung, saha lajeng & permintaan maaf kepada Tuhan yang \\
nyuwun sih pangapunten dhateng ngarsa & berbelas kasih mungkin saat hidupnya \\
Dalem Gusti ingkang Maha Welas mbok & saudara.....di dunia ini melakukan \\
\hline
\end{tabular}


bilih rikala sugengipun sedherek wonten ing alam donya manggihaken kalepatan ingkang ageng, ingkang alit, ingkang kasengaja utawi mboten kasengaja, mugi Gusti paring lunasing siksa saha kapapanaken wonten swarga langgeng, ngaso kanthi tentrem, dene brayat kang tinilar winantua berkah kawilujengan wiwit dinten punika ngantos ing salaminipun, kajurung pangestu saking para sedherek ingkang samya pilenggahan sedayanipun .................. kesalahan besar, kecil, yang disengaja atau tidak disengaja, semoga Tuhan melunaskan dari siksa serta ditempatkan di surga abadi, beristirahat dengan tenteram, sedangkan keluarga yang ditinggal senantiasa disertai berkah keselamatan mulai hari ini hingga selama-lamanya terdorong restu Anda semua yang duduk hadir di sini ...... (Amin).

Sebenarnya masih banyak simbol yang digunakan dalam tradisi ini. Jenang sengkala (jenang penolak bala) melambangkan kuasa Tuhan Yesus Kristus dapat menghapus dan menghilangkan semua bala. Jenang boning-baning (monangmaning) sebagai lambang kuasa Roh Kudus yang memberikan terang, kejernihan budi serta cerdasnya pikiran manusia. Jajan pasar sebagai ungkapan syukur kepada Tuhan yang sudah berkenan menciptakan bumi dan segala isinya. Tumpeng megana sebagai simbol jalan terciptanya alam semesta oleh Tuhan yang Mahakuasa dan tanah tempat tinggal manusia dijauhi dari segala mara bahaya. Semua doa ini dijawab umat dengan “inggih". Dalam konteks ini “inggih" memiliki makna yang sama dengan “amin”.
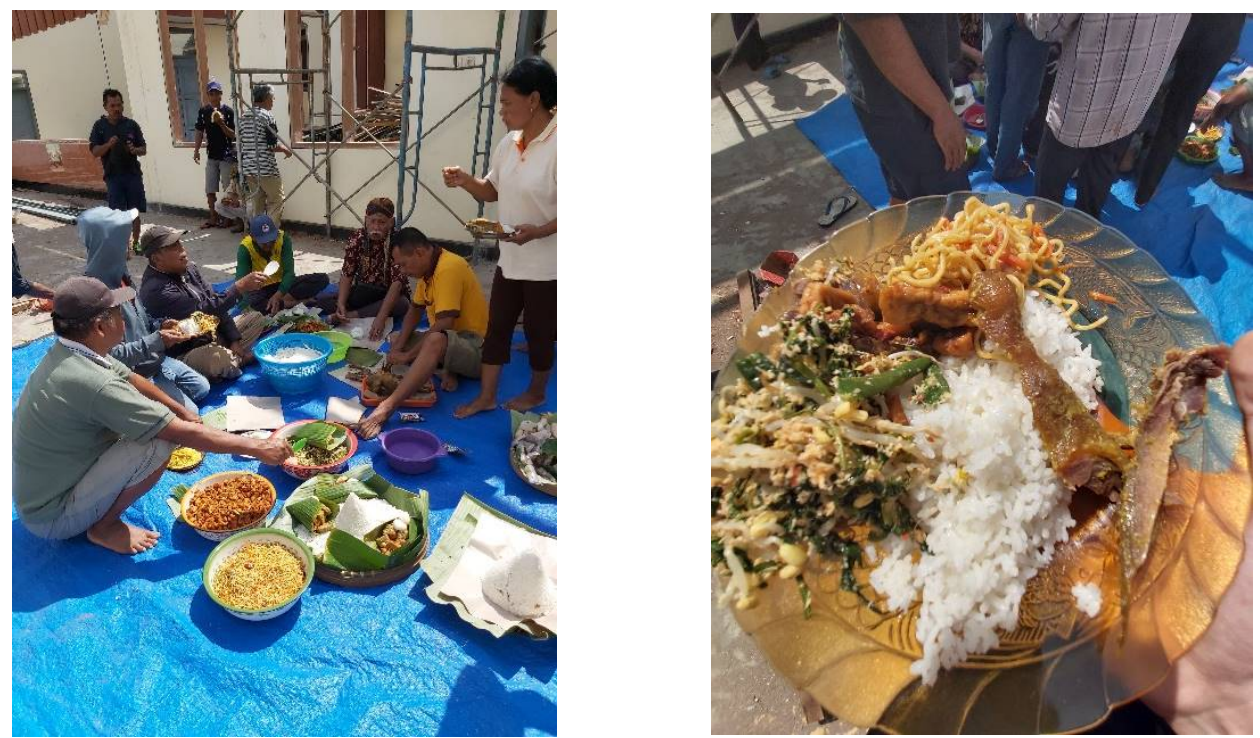

Pada bagian ketiga, jika ada seorang imam, semua makanan diberkati. Setelah itu semua makanan dibagikan kepada umat yang hadir. Semua makanan 
harus habis dan dibawa pulang ke rumah masing-masing. Mereka menyebutnya sebagai nasi berkat. Makanan ini akan membawa berkat.

Kemudian pengalaman yang kedua adalah kenduri pada misa arwah. Saat pertama kali mengikuti misa arwah, peneliti sedikit kaget. Makanan untuk kenduri disajikan begitu banyak. Bahkan ada 5 ayam ingkung berada di tengah umat. Nasi disediakan di dalam sebuah wadah besar dan jumlahnya mengikuti ayam ingkung yang ada. Yang berbeda di sini adalah tuan rumah yang mempunyai intensi untuk kedamaian arwah harus menyediakan makanan kenduri yang terbaik. Apa yang disajikan sama seperti kenduri saat unggah penuwun. Namun jumlah ayam ingkung harus sesuai jumlah anak. Jika ada seorang bapak meninggal dan mempunyai 5 anak, keluarga harus menyajikan 5 ayam ingkung.

Menurut peneliti, tradisi ini membutuhkan banyak biaya. Namun di tengah kekurangan, warga desa ikut membantu. Mereka menggunakan istilah rewang (membantu). Semua bergotong royong supaya kenduri bisa terlaksana. Jika kekurangan biaya, semua saling membantu. Rewangan biasanya dilakukan jika ada kematian atau pernikahan (Hasbullah 2012:232). Ada yang membantu menyiapkan tempat dan ada yang membantu masak. Para warga saling membantu dan kelak berharap jika mereka mengalami persoalan yang lain akan membantu. Rewangan itu seperti menabung untuk masa depan. Jika ada satu warga yang tidak pernah ikut rewang, kenduri atau acara desa lainnya, keluarganya pasti akan kesusahan karena warga desa tidak mau membantu (Dewi 2015:3). Hal ini membuktikan bahwa di dalam tradisi kenduri ada kontrol sosial (bdk. Cahyani et al. 2019:5).

\subsection{Pembahasan}

\subsubsection{Pelaksanaan Katekese dalam Tradisi Kenduri Umat Paroki Maria Ratu Damai Purworejo Malang}

Tradisi kenduri merupakan budaya umat Paroki Maria Ratu Damai. Katekese yang ada di dalam tradisi ini juga menggunakan simbol-simbol hasil bumi. Para katekis biasanya adalah para sesepuh desa sekaligus pemimpin dalam tradisi kenduri. Katekese ditemukan dalam bagian doa-doa yang dipimpin oleh sesepuh desa. Dari hasil penelitian menunjukkan bahwa para pemimpin selalu mengarahkan umat untuk bersyukur atas rahmat Tuhan dalam kehidupan seharihari. Salah satu sesepuh menyatakan bahwa doa yang dipanjatkan mengikuti ajaran Gereja Katolik. Hal ini merupakan suatu cara berkatekese kontekstual. Misteri penyelamatan Allah dijelaskan dalam simbol-simbol alam. Dengan harapan, umat akan lebih mudah memahami dan menanamkan ajaran tersebut dalam hatinya masing-masing.

Pelaksanaan kenduri biasanya dilakukan di rumah-rumah. Umat diajak untuk melihat kembali pengalaman iman sebagai umat Allah. Dalam hal ini 
katekese dalam tradisi kenduri bersifat sebagai komunikasi iman. Pengalaman iman akan kehidupan diharapkan memberikan kekuatan rohani. Secara khusus dialog pengalaman iman ini menggunakan bantuan simbol-simbol hasil alam. Peneliti berpendapat bahwa katekese tersirat dalam tradisi kenduri ini merupakan sebuah usaha berkatekese dengan pengalaman hidup sehari-hari. Mungkin saja dengan melihat ayam ingkung yang disajikan, umat akan mengingat kembali karya keselamatan Allah. Dengan melihat kue apem, umat mengingat kembali sifat kerahiman Allah. Hingga akhirnya umat mampu menghidupi karya keselamatan ini dengan budayanya masing-masing.

Selain itu unsur metonia (pertobatan) dalam kenduri sangat menonjol. Katekese juga memiliki tujuan untuk mengarahkan umat melakukan pertobatan hidup. Pertobatan sendiri berjalan seumur hidup. Dalam doa (ujub-ujub) kenduri umat Paroki Maria Ratu Damai Purworejo, pemimpin selalu mengingat umat akan karya penebusan Kristus kepada manusia. Dosa-dosa telah ditebus dan umat harus mempersembahkan diri seutuhnya. Jawaban “inggih" menjadi suatu jawaban keseriusan untuk melakukan pertobatan ini. Oleh sebab itu para katekis memiliki tugas untuk mengingatkan umat akan keseriusannya dalam menjalani pertobatan.

\subsubsection{Pelaksanaan Katekese Penghayatan Ekaristi dalam Tradisi Kenduri Umat Paroki Maria Ratu Damai Purworejo Malang}

Peneliti melihat bahwa tradisi kenduri yang dilakukan oleh umat Paroki

Maria Ratu Damai secara tidak langsung merupakan katekese penghayatan Ekaristi. Ekaristi adalah perayaan resmi iman Gereja. Semua umat berkumpul dan merayakan misteri paskah yang merupakan rahmat keselamatan bagi umat manusia. Dalam kenduri, nuansa persekutuan sangat kuat. Umat berkumpul di salah satu rumah, berdoa bersama, dan saling berbagi makanan yang telah diberkati. Doa yang dipanjatkan merupakan ucapan syukur atas karya keselamatan Allah melalui misteri paskah. Peneliti sebagai orang luar langsung melihat praktik ini memiliki kemiripan dengan perayaan Ekaristi. Dengan kata lain, paroki memiliki kesempatan besar untuk melakukan katekese penghayatan Ekaristi.

Penghayatan Ekaristi tidak bisa dilepaskan dari kehidupan sehari-hari. Paus Yohanes Paulus II menyatakan bahwa setiap kali Gereja merayakan Ekaristi, Gereja merayakan kelahirannya. Gereja kembali diingatkan sebagai sebuah persekutuan. Persekutuan ini bisa digambarkan sebagai Tubuh Mistik Kristus di mana Kristus adalah kepala dan Gereja adalah anggota tubuh. Nilai persekutuan merupakan nilai yang harus dijaga oleh umat paroki. Setiap umat tidak bisa hidup sendiri-sendiri.

Dalam kenduri, semua umat diajak untuk berkumpul dan berdoa. Dalam membuka acara, pemimpin selalu menjelaskan intensi kenduri. Semua orang diajak berkumpul untuk berdoa bersama. Persekutuan yang ingin ditekankan di 
sini adalah persekutuan doa. Berdoa bersama-sama memiliki nilai yang lebih tinggi. Di balik persekutuan doa ini, ada persiapan yang cukup matang. Tetangga atau kerabat dekat membantu mempersiapkan segala sesuatu. Tradisi rewang menjadi salah satu bukti bahwa umat paroki tidak jauh dari nilai persekutuan. Secara tidak langsung, pemimpin berkatekese tentang persekutuan Ekaristi.

Dalam perayaan Ekaristi, Gereja selalu mengenangkan kembali peristiwa paskah yaitu sengsara, wafat, dan kebangkitan Kristus. Peneliti melihat makna peristiwa paskah selalu ditekankan dalam ujub-ujub. Pemimpin menjelaskan bahwa persembahan yang disajikan di tengah-tengah umat merupakan ucapan syukur kurban keselamatan. Dalam teks doa kenduri pemimpin akan mengatakan “Ingkang satunggal aturan, sageda linambaran iman kapitayanipun, agami ingkang dipun ugemi dadosa sarana kangge nggayuh kasampurnaning gesang lantaran Sang Kristus, tumunten mbenjing saged ndherek ngraosaken wohing panebusan Dalem, amargi saking jurung pangestu saking para sedherek ingkang samya pilenggahan sedayanipun (Yang satu persembahan lagi, kurban sembelihan yang disampaikan merupakan lambang Tuhan Yesus Kristus yang telah bersedia sengsara, wafat dengan menuntaskan darah-Nya di Golgota sebagai tebusan dosa dunia untuk keselamatan umat semua mulai hari ini hingga selamalamanya terdorong restu Anda semua yang duduk hadir di sini).

Hal ini bisa menjadi salah satu bukti bahwa kenduri bisa menjadi salah satu sarana bagi umat untuk melihat kembali makna perayaan Ekaristi. Namun yang harus ditekankan adalah misteri keselamatan ini mendorong setiap pribadi untuk menjadi saksi Kristus. Dimensi eskatologis dalam perayaan Ekaristi mendorong Gereja untuk menjadi saksi yang selalu mewartakan keselamatan di tengah dunia. Kehidupan Gereja berkaitan erat dengan kehidupan surgawi. Dimensi ini begitu ditekankan oleh Paus Yohanes Paulus II. Dengan menyantap Tubuh dan Darah Kristus dalam perayaan Ekaristi, umat Allah mendapatkan jaminan kehidupan kekal. Oleh sebab itu umat Allah mengungkapkan persekutuan dengan Gereja Surgawi. Konsekuensi dari persekutuan ini adalah peziarahan umat Allah di dunia harus mencerminkan semangat eskatologis. Janji akan hidup baru di surga tidak mengurangi tanggung jawab manusia di dunia.

Pemimpin kenduri menyatakan bahwa "wilujengan kang ginelar punika mujudaken raos atur panuwun dhateng ngarsa Dalem Gusti ingkang Maha Kuwaos ingkang sampun anitahaken Ibu bumi Bapa akasa, Ibu wengi Bapa rina, Bapa Adam Ibu Kawa, para Santo, Santa lan para suci tumedhakipun dhumateng kawula dasih ingkang samya andon lampah wonten ing alam ndonya, mugi paringa berkah kawilujengan karaharjan, wiwit dinten punika ngantos ing salami-laminipun kajurung pangestu saking para sadherek ingkang samya pilenggahan sedayanipun"(Selamatan yang tersaji ini merupakan ungkapan rasa syukur terima kasih kepada Tuhan yang maha kuasa, yang telah menciptakan Ibu 
Pertiwi-Bapa Akasa, Ibu Malam-Bapa Siang, Bapa Adam dan Ibu Hawa, para santo-santa, serta para suci hingga masyarakat biasa yang sedang berziarah di dunia. Semoga berkah keselamatan dan kesejahteraan, mulai hari ini sampai selama-lamanya terdorong restu Anda semua yang sedang hadir). Hal ini merupakan sebuah ungkapan eskatologis. Sesuai dengan semangat Paus Yohanes Paulus II, peneliti melihat bahwa secara tidak langsung katekese dalam kenduri ingin mendorong umat untuk menyadari peziarahan umat Allah di dunia harus mencerminkan semangat eskatologis. Setiap umat memiliki tanggung jawab untuk menciptakan suasana kerajaan Allah di dunia.

Katekese penghayatan Ekaristi dalam kenduri sebenarnya menekankan bahwa semangat Ekaristi tidak boleh berhenti di altar saja. Dalam konteks Indonesia, hubungan Ekaristi dengan kehidupan sehari-hari sering digambarkan dengan metafora altar dan pasar. Peneliti berpendapat katekese dalam tradisi kenduri merupakan usaha umat untuk mengaitkan hidup ekaristi di tengah "pasar". Semua doa dan simbol yang digunakan adalah usaha untuk menerjemahkan semangat Ekaristi di kehidupan sehari-hari. Dalam perayaan Ekaristi, umat Allah berdoa, mengucapkan puji dan syukur, menyantap Tubuh dan Darah Kristus, dan akhirnya siap diutus ke tengah dunia. Katekese dalam tradisi kenduri mau mengingatkan umat bahwa karya keselamatan Allah harus bergema dalam setiap dimensi kehidupan manusia.

\subsubsection{Analisis Konsep Katekese dalam Kenduri Menurut Teori Shared Praxis}

Pada bagian ini, peneliti akan menganalisis pelaksanaan katekese penghayatan Ekaristi dalam tradisi kenduri. Pertama-tama yang harus ditekankan adalah pendekatan share praxis tidak bersifat kaku. Paroki Maria Ratu Damai memiliki konteks budaya Jawa. Katekese dalam tradisi kenduri harus dianalisis dalam konteks kebudayaan Jawa. Para katekis atau sesepuh desa berkatekese menggunakan simbol-simbol hasil bumi. Simbol ini merupakan bagian kehidupan sehari-hari umat paroki. Hal ini bisa dilihat sebagai usaha untuk membawa iman kepada kehidupan dan kehidupan kepada iman.

Tradisi kenduri sebagai sarana berkatekese sesuai dengan prinsip dasar yang ditekankan oleh Groome. Kenduri menuntut adanya sebuah komunitas. Komunitas merupakan wadah bagi setiap umat untuk berdialog dan merefleksikan iman. Dengan kata lain, komunitas umat paroki menjadi wadah dinamika iman. Umat diharapkan bisa mengidentifikasi dirinya sebagai orang yang harus memiliki iman yang hidup dan berbagi. Ujub-ujub menjadi sarana untuk merefleksikan pengalaman iman dan pembagian nasi berkat menjadi simbol berbagi dalam komunitas. 
Groome telah menyatakan bahwa praxis merupakan sebuah proses di mana umat diajak untuk melihat Tuhan selalu menampakkan Diri-nya dalam kehidupan sehari-hari. Praxis dalam kenduri bisa digambarkan seperti ini. Mungkin saja dengan melihat ayam ingkung yang disajikan, umat akan mengingat kembali karya keselamatan Allah. Dengan melihat kue apem, umat mengingat kembali sifat kerahiman Allah. Hingga akhirnya umat mampu menghidupi karya keselamatan ini dengan budayanya masing-masing.

Praxis untuk katekese umat penghayatan Ekaristi tidak bisa dilepaskan dari simbol-simbol. Kebudayaan Jawa kaya akan simbol-simbol atau lambanglambang. Menurut peneliti, para katekis awali Paroki Maria Ratu Damai mampu melihat kekuatan ini. Memang dalam hal ini perlu dilakukan penelitian lebih lanjut. Namun dari pengalaman observasi langsung, peneliti melihat umat lebih bersemangat untuk mengikuti kenduri. Orang Jawa terbiasa menyampaikan simbol-simbol yang lebih konkret untuk menyampaikan ide dan gagasannya. Oleh sebab itu kehadiran katekis yang mampu menjadi penutur ujub-ujub sangat dibutuhkan. Paroki juga perlu memikirkan hal ini sebagai evaluasi pelaksanaan katekese umat.

Berikutnya adalah dinamika share. Shared menekankan dinamika komunal yang ditemukan dapat proses katekese. Dinamika komunal yang dimaksud adalah dialog dan integrasi antara tradisi dan visi (situasi sekarang) partisipan dan Tradisi dan Visi Kristiani di dalam komunitas. Groome menekankan perlunya proses ini untuk saling mendengarkan, bertukar pikiran, berbagi pengalaman, mengutarakan pendapat dan sebagainya. Dinamika komunal dalam tradisi kenduri sedikit berbeda dengan teori ini.

Dialog iman dapat ditemukan dalam ujub-ujub. Namun pemimpin lebih memiliki peran dominan. Penjelasan sekaligus doa dilakukan oleh pemimpin dan umat menjawab inggih. Dalam konteks ini “inggih" memiliki makna yang sama dengan “amin”. Tradisi dan Visi Kristiani yang diutarakan pemimpin adalah misteri paskah. Umat mendengarkan sambil memperhatikan simbol-simbol yang berada di tengah mereka. Groome sendiri menekankan perlunya dialog antarpartisipan. Mereka bertukar pikiran dan berbagi pengalaman. Permasalahannya adalah tradisi kenduri tidak menggunakan metode dialog seperti itu. Dinamika komunal menurut Groome perlu dimodifikasi sesuai dengan konteks tradisi kenduri.

Dalam kenduri kematian, umat Paroki Maria Ratu Damai biasanya meminta pelayanan misa. Misa arwah dilaksanakan sebelum tradisi kenduri. Jika imam berhalangan hadir, para asisten imam akan memimpin ibadat sabda. Menurut peneliti, kesempatan ini bisa digunakan untuk memperdalam Tradisi dan Visi Kristiani. Dengan demikian, saat kenduri dilaksanakan umat dapat memperoleh pemahaman yang lebih mendalam. Homili atau renungan yang 
disampaikan harus membuka pemahaman umat bahwa ada makna rohani di dalam kenduri ini. Umat pun diajak untuk menghayati lebih mendalam jawaban "inggih".

Untuk mengatasi kekurangan dinamika share, petugas pastoral dapat melaksanakan program katekese seperti pendalaman iman atau lectio divina dari rumah ke rumah. Peneliti menawarkan sebuah konsep untuk pelaksanaan katekese ini. Konsep ini mengikuti pendekatan Groome. Ada 5 langkah yaitu

\begin{tabular}{|c|c|}
\hline dup & $\begin{array}{l}\text { Para peserta dibimbing untuk melihat pengalaman mengikuti } \\
\text { acara kenduri. Pemimpin mengajak beberapa umat untuk } \\
\text { bercerita bagaimana pengalamannya. }\end{array}$ \\
\hline $\begin{array}{l}\text { Langl } \\
\text { Refle } \\
\text { pada }\end{array}$ & $\begin{array}{l}\text { untuk merefleksinya secara kritis. Di sini pemimpin memberikan } \\
\text { penjelasan nilai-nilai penghayatan Ekaristi yang sudah sering } \\
\text { dilakukan dalam kenduri. Para peserta diajak melihat } \\
\text { pengalamannya dari sudut pandang baru. }\end{array}$ \\
\hline $\begin{array}{l}a \\
\text { si }\end{array}$ & $\begin{array}{l}\text { Para peserta diajak untuk mendalami ajaran iman Kristiani } \\
\text { sebagai sumber spiritual kehidupan. Peneliti mengusulkan untuk } \\
\text { menggunakan metode lectio divina sederhana. Pemimpin bisa } \\
\text { menggunakan bacaan Kis 4:32-37. Cara hidup jemaat pertama } \\
\text { sangat mirip dengan tradisi kenduri. Pemimpin akan menjelaskan } \\
\text { kesamaannya dan menyadarkan para peserta bahwa mereka telah } \\
\text { melakukannya melalui tradisi setempat. }\end{array}$ \\
\hline npat & $\begin{array}{l}\text { Pembatinan dapatkan dilakukan dengan meditasi singkat. Umat } \\
\text { diajak untuk berefleksi secara pribadi. Kemudian pemimpin } \\
\text { mengajak para partisipan untuk membagikan refleksinya. } \\
\text { Pemimpin harus menciptakan suasana yang mendukung agar } \\
\text { setiap peserta bisa berdialog satu sama lain. }\end{array}$ \\
\hline $\begin{array}{l}\text { Langkah Kelima } \\
\text { Niat Pribadi }\end{array}$ & $\begin{array}{l}\text { Pemimpin mengajak peserta untuk menuliskan niat-niat yang } \\
\text { akan dilaksanakan. Secara khusus pemimpin bisa mengarahkan } \\
\text { mereka untuk memperkuat persekutuan ekaristi. Bagaimana umat } \\
\text { mampu saling berbagi satu sama lain, menolong tetangga, dan } \\
\text { sebagainya. }\end{array}$ \\
\hline
\end{tabular}

Langkah-langkah ini bisa dimodifikasi sesuai dengan kebutuhan. Peneliti sangat menyarankan adanya program katekese pendalaman iman ini. Dengan program ini, katekese penghayatan Ekaristi dalam tradisi kenduri dapat disempurnakan. Umat paroki dapat menjadi komunitas yang hidup sekaligus saksi Kristus di tengah masyarakat. Mereka telah memiliki modal besar yaitu katekese kontekstual. Dengan tradisi kenduri, mereka diharapkan mampu menemukan identitasnya sebagai seorang murid Kristus yang siap diutus untuk mewartakan perdamaian sesuai dengan bahasa mereka sendiri. 


\section{KESIMPULAN}

Tradisi kenduri yang dilakukan oleh umat Paroki Maria Ratu Damai secara tidak langsung merupakan katekese penghayatan Ekaristi. Katekese penghayatan Ekaristi dalam kenduri sebenarnya menekankan bahwa semangat Ekaristi tidak boleh berhenti di altar saja. Semua orang diajak berkumpul untuk berdoa bersama. Persekutuan yang ingin ditekankan di sini adalah persekutuan doa. Katekese ini menggunakan simbol-simbol hasil alam yang sangat dekat dengan kehidupan sehari-hari umat. Praxis dilakukan dengan bantuan simbol-simbol ini. Namun dimensi share masih kurang nampak dalam pelaksanaan katekese ini. Petugas pastoral dapat melaksanakan program katekese seperti pendalaman iman dari rumah ke rumah agar dapat berdialog lebih mendalam satu sama lain.

\section{DAFTAR PUSTAKA}

Arifianto, Deno, Nurman Nurman, dan Susi Fitria Dewi, 2018, “Nilai-Nilai Moral dan Sosial dalam Penyelenggaraan Kenduri Sudah Tuai di Desa Kumun Mudik Kota Sungai Penuh", dalam Journal of Civic Education 1 (3): 27279.

Cahyani, Fisca, Ravik Karsidi, dan Drajat Kartono, 2019, "Kenduri: Traditional Culture in The Modern Society", dalam Seword Fressh 27 (1).

Dewi, Sri Puspa, 2015, “Tradisi Rewang dalam Adat Perkawinan Komunitas Jawa di Desa Pepatahan Jaya SP-1 Kecamatan Tapung Kabupaten Kampar", dalam Jom Fisip 2 (2): 1-14.

Groome, Thomas, 2018, "Traces That Remain: From Life to Faith to Life", dalam Religious Education 113 (2): 147-55.

Groome, Thomas H., 2006, A Shared Praxis Approach to Religious Education dalam International Handbook of the Religious, Moral and Spiritual Dimensions in Education diedit oleh M. De Souza, G. Durka, K. Engebretson, R. Jackson, dan A. McGrady. Dordrecht: Springer International Publishing AG.

Hasbullah, 2012, "Rewang: Kearifan Lokal dalam Membangun Solidaritas dan Integrasi Sosial Masyarakat di Desa Bukit Batu Kabupaten Bengkalis", dalam Jurnal Sosial Budaya 9 (2): 231-43.

Jelahu, Timotius Tote, 2016, "Gagasan Kontekstualisasi Terjemahan Dalam Penguatan Katekese Umat", dalam Jurnal Sepakat 2 (2): 168-81.

John Paul II., 2003, "Ecclesia de Eucharistia", dalam http://www.vatican.va/content/john-paulii/en/encyclicals/documents/hf_jpii_enc_20030417_eccl-de-euch.html, diakses pada 4 April 2021 pukul $10.00 \mathrm{WIB}$ 
Johnson-Miller, Beverly C., dan Benjamin D. Espinoza, 2018, “Catechesis, Mystagogy, and Pedagogy: Continuing the Conversation", dalam Christian Education Journal 15 (2): 156-70.

Kelen, Donatus Sermada., 2018, Tradisi Semana Santa: Suatu Bentuk Katekese yang Hidup dalam Pembaharuan Gereja Melalui Katekese: Superfisialisme, Aktivisme, Fundalisme, dan Spiritualisme Tantangan Katekese Dewasa ini, diedit oleh R. P. Manik, A. Saptowidodo, dan A. S. Budianto. Malang: STFT Widya Sasana.

Mahon, Katharine, 2018, "Serving the new evangelization: Opportunities and challenges in catechesis and pastoral ministry in the vision of Pope Francis", dalam Liturgy 33 (2): 20-27.

Manik, Robert Pius., 2018, Ritual Maggid sebagai Model Berkatekese dalam Pembaharuan Gereja Melalui Katekese: Superfisialisme, Aktivisme, Fundalisme, dan Spiritualisme Tantangan Katekese Dewasa ini, diedit oleh R. P. Manik, A. Saptowidodo, dan A. S. Budianto. Malang: STFT Widya Sasana.

Martasudjita, E. P. D, 2013, “Hubungan Ekaristi dengan Hidup Sehari-hari dalam Teologi Sakramental Karl Rahner", dalam Diskrusus 12(2):278-301.

Muhammad Nurul Fadillah, Harles Anwar, Siti Zainab, 2020, "Tradisi Kenduri Kematian di Desa Kampung Baru, Kabupaten Katingan", dalam Syams: Jurnal Studi Keislaman 1 (2): 1-9.

Muhayir, 2018, "Makna Tradisi Kenduri Kematian Di Pulau Terong Kota Batam", dalam Diakromika 19 (2): 1-91.

Nagle, James Michael, 2019, "Learning to Leave: Expanding Shared Praxis to Understand the Religious Life and Learning of Young Catholics Beyond the Church", dalam Religious Education 114(4):528-43.

Pranyoto, Yohanes Hendro, 2018, "Pokok-pokok Penyelanggaraan Katekese: Analisis Dokumen Catechesi Tradendae", dalam Jumpa 6 (1): 53-67.

Prastyo, Randa Dwi, dan Maryaeni, 2017, "Mantra Kenduri Matang Puluh Dina Dusun Dadapan Kecamatan Pagak Kabupaten Malang", dalam Satwika: Kajian Ilmu Budaya dan Perubahan Sosial 1 (2): 29-40.

Purwandaru, Pandu, Dudy Wiyancoko, dan Akira Ueda, 2016, "The Culture of Postharvest Rice Plant Utilization in JavanesE Community", dalam Bulletin of JSSD 63 (4): 69-78.

Ristanto, Dwi Andri, 2020, "Dimensi Sosial Ekaristi Yohanes Paulus II dan Benediktus XVI", dalam Jurnal Teologi 9 (2): 119-42.

Yurisma, Dhika Yuan, dan Bahruddin Muhammad, 2020, "Pemaknaan Simbol Reog Ponorogo Dalam Tradisi Jawa: Sebuah Kajian Kritis", dalam Bricolage : Jurnal Magister Ilmu Komunikasi 6 (01): 101. 